\title{
Guidelines for Publication of Voltage Quality Monitoring Results in Portugal: A Regulatory Perspective
}

\author{
S. Faias ${ }^{1,2,3}$ and J. Esteves ${ }^{1,2}$ \\ ${ }^{1}$ Entidade Reguladora dos Serviços Energéticos (ERSE) \\ Rua Dom Cristóvão da Gama, 1 - 3º 1400 - 113 Lisboa (Portugal) \\ Phone number:+351 213033 200, e-mail: SFaias@erse.pt, JEsteves@erse.pt \\ ${ }^{2}$ Lisbon Engineering Superior Institute (ISEL) \\ Rua Conselheiro Emídio Navarro, 1, 1950-062 Lisboa (Portugal) \\ ${ }^{3}$ INESC ID \\ Rua Alves Redol, 9, 1000-029 Lisboa (Portugal)
}

\section{Key words}

Voltage quality, monitoring, power quality, regulation code.

\section{Introduction}

The quality of service regulation, also referred to as quality of electricity supply regulation, with its three dimensions, continuity of supply (network reliability and availability), power or voltage quality (characteristics of the supply voltage) and commercial quality (timeliness in dealing with customers' requests) provides a balance between customers' willingness to pay network tariffs and their expectations on minimum levels of quality of service [1][3].

This quality of electricity supply regulation can be exercised with recourse to a set of direct and indirect instruments such as the definition of minimum standards for the continuity of supply indicators and respective individual monetary compensations, financial incentive schemes, regular reporting and dissemination of the network performance, national and international benchmarking and implementation of national voltage quality monitoring programs [1], [4]-[7].

Regarding the voltage quality topic, the implementation of national monitoring programs is one of the main instruments that can be used by the regulatory authorities. According to the Council of European Energy Regulators (CEER), it is recommended that counties encourage network operators to continuously monitor voltage quality. With the implementation of those programs it becomes possible to verify compliance with voltage quality requirements (both overall and for individual customers), to provide information to customers on their actual or expected voltage quality and to obtain information for the setting of appropriate future requirements [8].

Thus, one of the main components of a voltage quality monitoring program is the reporting and publishing of the results. For this purpose, the internet seems to be a common and powerful platform for the publication of data. In addition to the website of the national regulatory authorities, results should be published on the respective websites of network operators as well. However, that reporting should be harmonised and standardised and the respective obligations should be clearly legally defined [6].

The objective of this paper is to present an overview on the Portuguese quality of electricity supply code, in what concerns the voltage quality topic. To present and compare the different practices adopted by each network operator to publish the results from its voltage quality monitoring program and, finally, to present some guidelines for reducing the lack of harmonization identified and to make the published results more useful.

\section{Regulation of the Quality of Electricity Supply in Portugal}

In Portugal, the first steps towards the electricity sector liberalization started in 1995. As a result, with the objective of defining the minimum quality of service standards that utilities should provide to customers and the practices used to monitor the compliance with those standards, the government published the first Portuguese code on the quality of electricity supply in the year 2000. This code, comprising the continuity of supply, voltage quality and commercial quality aspects, was revised in the years 2003 and 2006. 
Until 2012, the role of the Portuguese regulatory authority on the quality of electricity supply topic was limited to the supervision of compliance with the quality of electricity supply code and to the definition of regulatory incentives.

New legislation published in September and October 2012 transferred to ERSE the authority to prepare and approve the national regulatory framework on the quality of electricity supply. In this regard, during 2013, ERSE promoted a revision of the quality of electricity supply code.

During this code revision, initiated in January 2013, ERSE identified the different stakeholders (customers, network operators, suppliers, academics and other specialists) and promoted a set of meetings with the objective of collecting their proposals. In addition, in April 2013, ERSE organized a workshop dedicated to continuity of supply and power quality subjects with the participation of some international specialists. In June 2013, ERSE published a first proposal for the new quality of electricity supply code, promoted a public consultation and started the collection of comments to improve that first code proposal. The final version of the code was published in November 2013 and came into force in January 2014.

It should be referred that in this code revision process, beyond the proposals received from the different stakeholders, several valuable inputs gathered from the different technical reports produced by CEER were also included, as for instance the different editions of the Benchmarking Report on the Electricity Quality of Supply and some of the Guidelines of Good Practices, as well as other technical reports and international standards published by CENELEC and IEC.

During quality of electricity supply code revision, the different stakeholders identified the need to maintain the participation and interactivity level promoted by ERSE, in what concerns the quality of supply topic. In this sense, a working group to follow the application of the new quality of electricity supply code and to gather inputs for future code revision processes was created and it has been active since March 2014 [9].

\section{Voltage Quality Monitoring in Portugal}

Voltage quality is an important aspect of the quality of electricity supply that network operators provide to their connected customers. When voltage quality is poor, problems such as reduced life-time, loss of efficiency, flickering lights and even explosion or fire can arise in the use of electrical appliances and equipment.

In this sense, the quality of electricity supply code establishes that under regular conditions of operation, network operators must monitor the supply voltage characteristics and maintain some of such characteristics in compliance with the limits defined in the international standard EN 50160: 2010 for the high-voltage (HV), medium-voltage (MV) and low-voltage (LV) levels. For the extra-high-voltage (EHV) level, the Portuguese quality of electricity supply code has an annex with the definition of the limits for the supply voltage characteristics.

In accordance to the quality of electricity supply code, the voltage characteristics that the network operators must monitor are the following:

- Continuous phenomena

o Frequency;

o Supply voltage variations;

o Harmonics;

o Unbalances;

o Flicker;

- Events

$\begin{array}{ll}\text { o } & \text { Dips; } \\ \text { o } & \text { Swells. }\end{array}$

For this purpose, network operators must develop voltage quality monitoring programs every two years, based on permanent monitoring and periodic campaigns. Those biannual programs must be submitted to the regulatory authority for approval.

As presented in Figure 1, the quality of electricity supply code imposes different requirements for the monitoring programs, according to the voltage levels of the network. As such, while for the EHV, HV and MV levels, continuous phenomena and voltage events must be monitored, for the LV networks only continuous phenomena monitoring is mandatory.

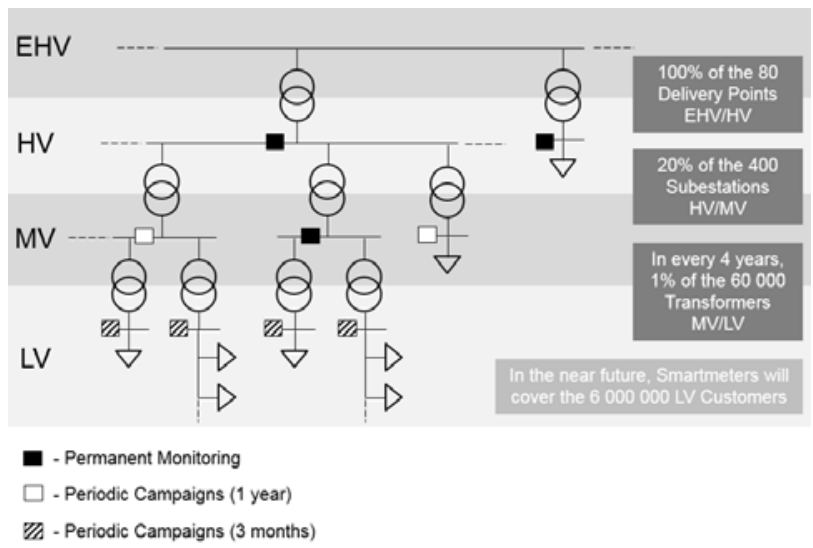

Fig. 1. Architecture of the Portuguese Voltage Quality Monitoring Program for the year 2017.

The code also establishes the minimum number of network points that must be covered by the voltage quality monitoring program in each voltage level. For the year 2017 the program must include permanent monitoring at $100 \%$ of the 80 delivery points of the transmission network (measured in the HV buses of the EHV/HV substations) and a combination of permanent monitoring and periodic campaigns of 1 year at $20 \%$ of the 400 delivery points of the $\mathrm{HV}$ and MV distribution networks (measured in the MV buses of the HV/MV substations). For the LV networks, in every 4 years, at least two of the 60000 different $\mathrm{MV} / \mathrm{LV}$ transformers must be monitored, by municipality. In this case, the 
measurement is performed at the LV buses for a period of 3 months. By now, the coverage of the LV networks monitoring is not much ambitious, because whenever a customer complains, network operators must perform a measurement of the voltage characteristics and, moreover, it is planned that in the next five years the 6 million LV customers will be equipped with Smartmeters able to measure the most continuous phenomena.

After the approval by the regulatory authority, voltage quality monitoring programs must be published in the web pages of the network operators. Also the results of the voltage quality monitoring must be published in the web page, disaggregated by monitored network point in a regular basis. Besides that publication, in the end of the year, operators must report all results to the regulatory authority.

\section{Benchmarking the Network Operators Practices on the Publication of Results}

The quality of electricity supply code imposes the obligation of network operators to publish the voltage quality monitoring results in their web pages. Consequently, the Portuguese system operators already started to publish the monitoring results on their webpages. However, since the quality of electricity supply code does not define any guidelines for the publication of such results, as presented next, different practices were adopted by each operator.

\section{A. Transmission System Operator}

The transmission system operator, as required by the quality of electricity supply code, publishes the results of voltage quality monitoring program in its webpage. This publication includes a list of the delivery points covered by monitoring and the respective reports with the results [9].

Each report includes the identification of the delivery point, the voltage level of the monitored bus or buses, the measuring period and the results for the different voltage characteristics. For the continuous phenomena, as presented in Figure 2, the results are published per week according to a colour labelling system.

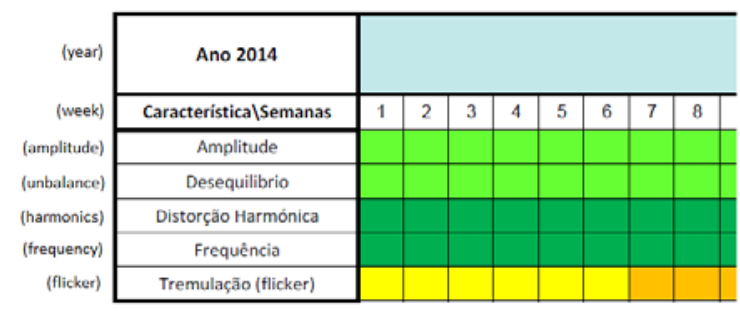

Fig. 2. Publication of results for continuous phenomena in EHV/HV delivery points (adapted from [10]).

The labelling system used by the operator comprises six different colours and has the objective of making the analysis understandable for the most of people. According to [11], this characterization system was initially developed in [12] and [13], inspired in the labels used for the energy efficiency characterization of domestic electrical devices.

As presented in Figure 3, the colours vary from dark green (very good quality) to red (bad quality) according to the value of a voltage quality index.

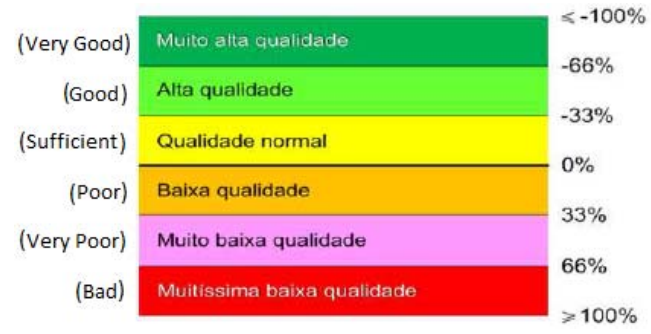

Fig. 3. Labeling system developed by the operator to characterize continuous phenomena (adapted from [10]).

The colour of the label depends on the value of the voltage quality index $i(p, l, f)$, used to characterize each one of the continuous phenomena. The calculation of this index is presented in (1).

$$
i_{(p, l, f)}(\%)=\left(\frac{n_{(p, l, f)}}{l_{(p)}}-1\right) \times 100
$$

Where $n(p, l, f)$ corresponds to the level of the voltage characteristic $p$, at phase $l$ of bus $b$, and $l(p)$ corresponds to the limits established for the characteristic $p$ by the quality of electricity supply code.

For harmonic voltages, the voltage quality index is determined based on the THD characteristic.

The main disadvantage of this methodology is that, for voltage characteristics that have upper and lower regulatory limits, there is no information about which one of those limits is imposing the colour of the label.

Regarding the voltage events, since no regulatory limits are established, this labelling system is not applied. The results of the voltage events monitoring are published based on the tables defined by the Portuguese code (adopted from standard EN 50160: 2010), which aggregate the events according the maximum deviation from the declared voltage and the duration of the events.

\section{B. Distribution System Operator}

The main Portuguese distribution system operator (HV, MV and LV networks), which supplies more than 99\% of the 6 million LV customers, implemented a system for the publication of the voltage quality monitoring results based on an interactive map. As presented in Figure 4, the map identifies all the network points covered by the monitoring program and allows the user to select any point and have access to the results of the measurements [14].

The report available for each network point includes the identification of the delivery point, the voltage level of 
the monitored bus or buses, the measuring period and the results for the different voltage characteristics.

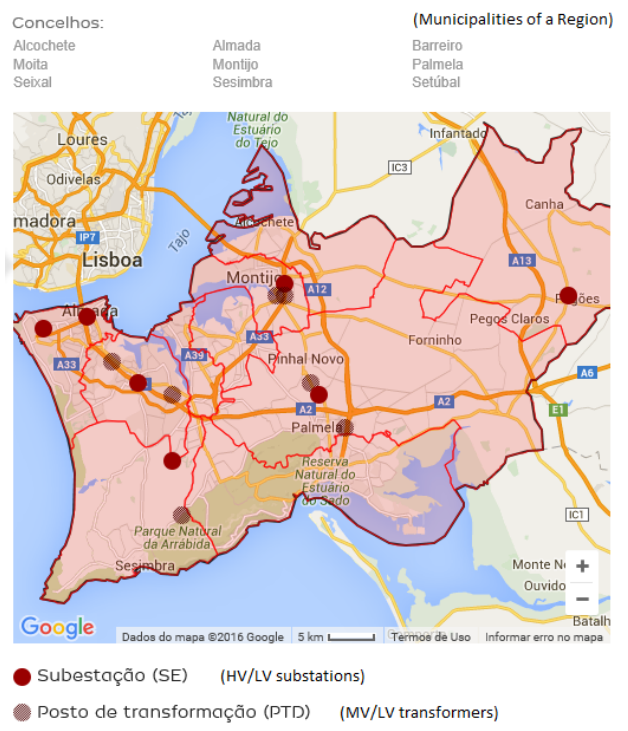

Fig. 4. Map with location of network points covered by the voltage quality monitoring program (adapted from [14]).

For continuous phenomena, the results for each voltage characteristic are presented in a bar chart (Figure 5) with the percentage of the $10 \mathrm{~min}$ records that are in compliance with the limits established by EN 50160: 2010.

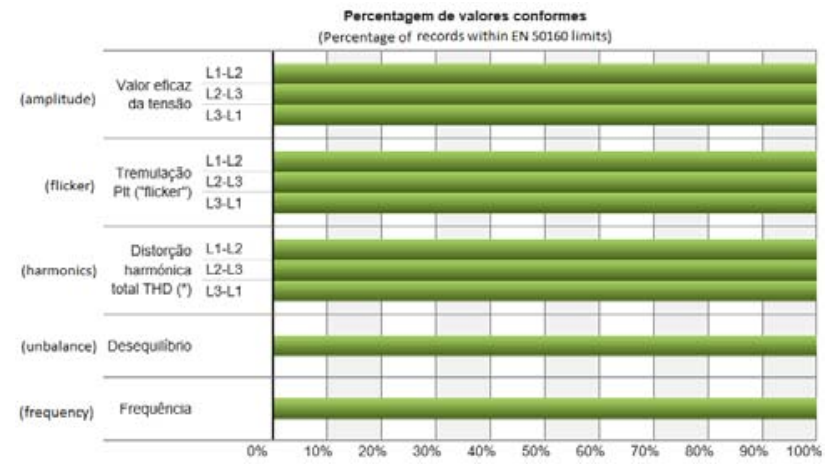

Fig. 5. Example of results publication for continuous phenomena in HV/MV delivery points and MV/LV transformers (adapted from [14]).

In spite of the reference to EN 50160:2010, this solution for continuous phenomena publication is not completely aligned with that standard. The approach used in the standard is based on the "week in compliance" with the limits and not based on the compliance of each $10 \mathrm{~min}$ records.

Moreover, publication of results only based on the compliance or not with the standard could not be enough for the network users. For instance, a given voltage characteristic can be in compliance with the standard, but very close to the limit. According to the approach used by the distribution system operator, that information is not made available for the customers. Also the evolution of the voltage characteristics along the year is not possible to follow with this approach.
For the publication of the voltage events, the approach is the same that is used by the transmission system operator, based on the EN 50160: 2010 tables for voltage dips and swells.

\section{Distribution System Operator exclusively in $L V$}

In Portugal mainland, besides the largest distribution system operator, there are 10 smaller companies operating exclusively LV networks. From those, CEVE is the one supplying more customers, about 9 thousands.

This operator exclusively in LV, as presented in Figure 6, has also implement a map in its webpage with the identification of the network points covered by the respective voltage quality monitoring program [15].

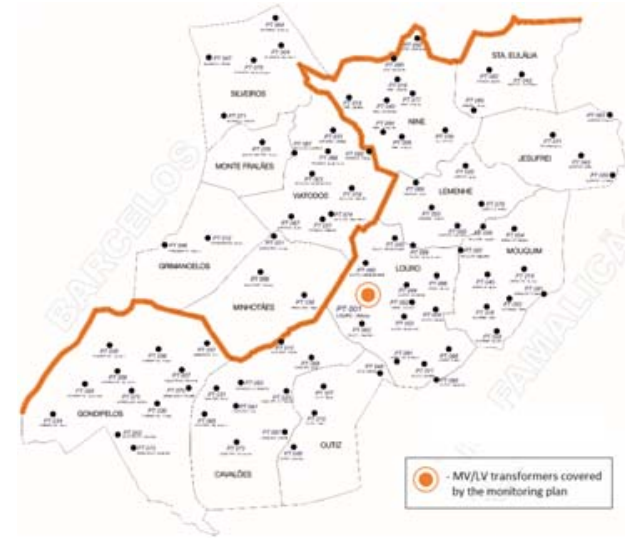

Fig. 6. Map with location of the MV/LV transformers covered by the voltage quality monitoring program (adapted from [15]).

As presented in Figure 7, the results of monitoring are reported with a labelling system based on a scale of six colours, from red (bad quality) to dark green (very good quality), equivalent to the one developed by the transmission system operator.

Since the Portuguese quality of electricity supply code does not impose the monitoring of voltage events for LV networks, such data is not reported by this network operator.

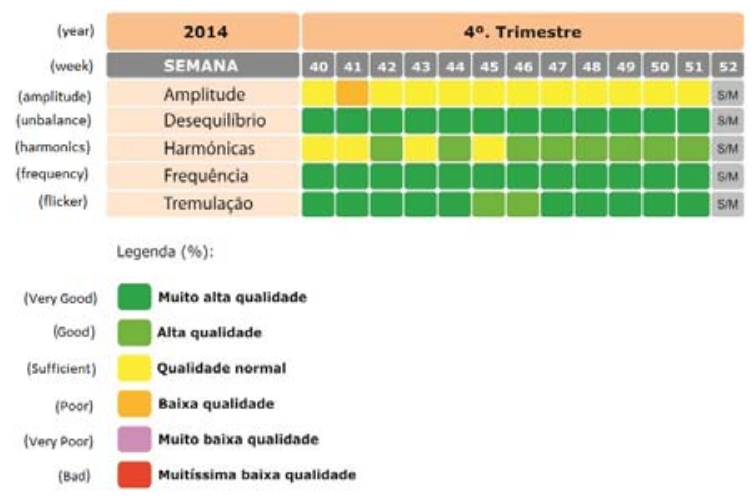

Fig. 7. Publication of results for continuous phenomena in MV/LV transformers (adapted from [15]). 


\section{Some Guidelines for Publication of the Monitoring Results}

The main objective for publication of the voltage quality monitoring results is to make available performance data of the grid to its users, specially for industrial customers. This data is important for present users of grid, to better understand voltage perturbations that are affecting their installations, but it is also essential for future grid users, when they need to select the location and the connection point for their installation and to design protection tools that immunize such installation to the most frequent perturbations.

According to this objective of making the monitoring results more useful for the grid users, some guidelines for their publication are presented next.

\section{A. Continuous Phenomena}

For the grid users perspective, it is important to know if, in their connection point, continuous phenomena such as frequency, supply voltage variations, harmonics, unbalances and flicker are in compliance with the limits established by the EN 50160: 2010. However, it is also important to know how far those voltage characteristics are from the established limits and how is the evolution of those characteristics along the year.

According to this perspective, it is proposed that the publication of the voltage quality monitoring results make use of a combination of information about the compliance with the limits established by the standard and the evolution of the voltage characteristics along the year.

For the analysis of the compliance with the standard, the approach must be based on the set of records of the week, as presented in Figure 8, and not on single records of 10 $\min$.

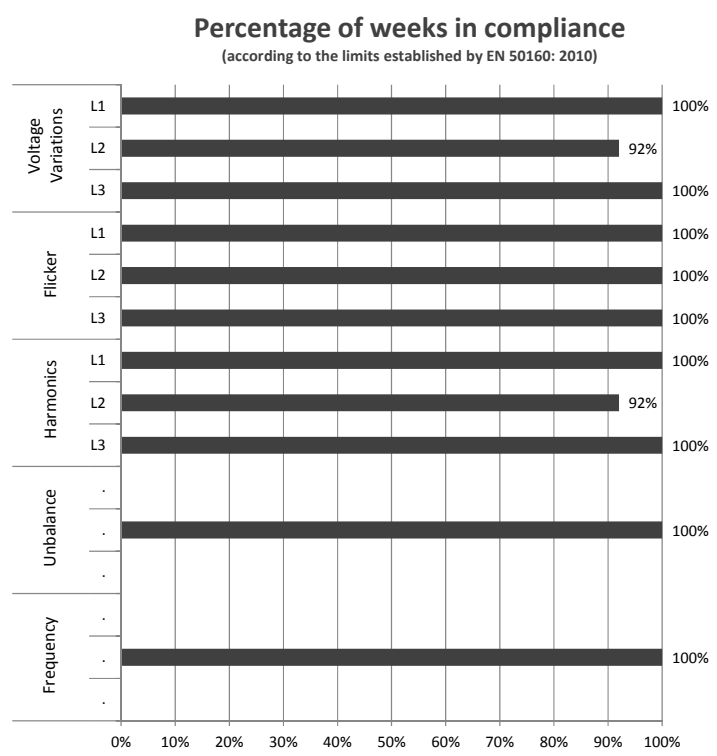

Fig. 8. Proposal for reporting the percentage of weeks in compliance with the standard during the monitoring period.
Since, for obtaining the previous results, a set of valuable information is gathered for each voltage characteristic, it is proposed to make available some of such information.

As example, it is considered a set of 10 min records of the mean rms voltage gathered from a LV network $(230 \mathrm{~V})$, as presented in Figure 9. Measurements were performed in the fourth week of December 2015 in a network that mainly supplies households in the Oeiras municipality, Portugal.

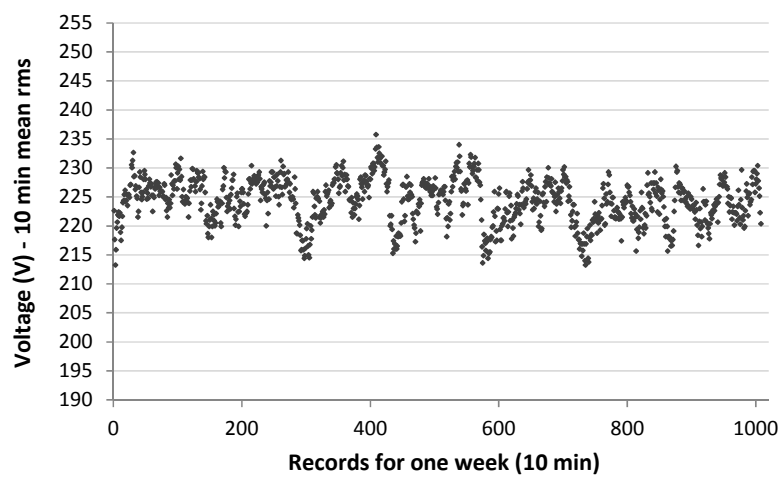

Fig. 9. Supply voltage variations for a single phase on a LV bus during one week.

When the 1008 records of 10 min mean rms are sorted to verify compliance with the standard limits, as presented in Figure 10, it is also possible to determine the average, maximum and minimum values of that records, and use them to characterize how far the supply voltage is from the regulatory limits.

The use of maximum and minimum values is a reasonable solution for the voltage quality characterization, since the records gathered and analysed correspond to the 10 minutes mean rms values of the voltage and, according to the EN 50160: 2010 standard, should only include normal operating conditions. As such, the influence of outliers or any measurement errors is previously minimised.

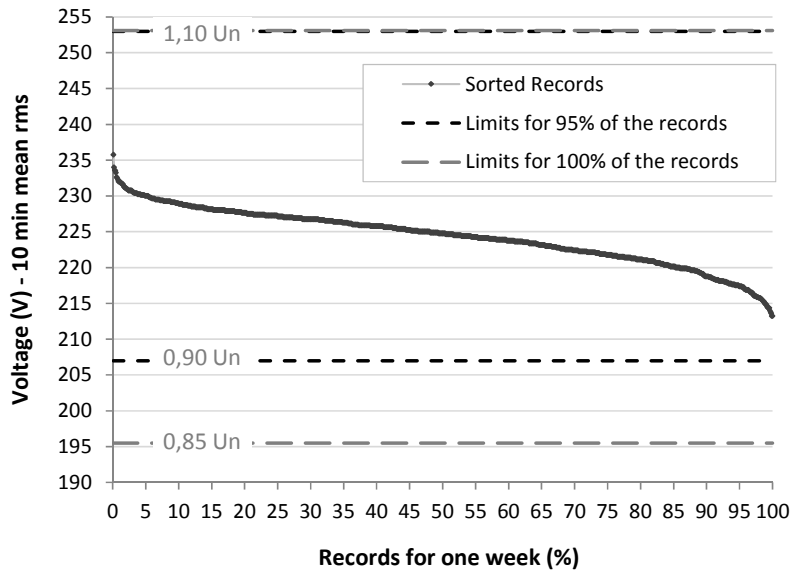

Fig. 10. Comparison of the 10 min mean rms values with the limits established by the EN 50160: 2010. 
The information obtained from the sorted records, as for instance the average, maximum and minimum values, are presented in Figure 11.

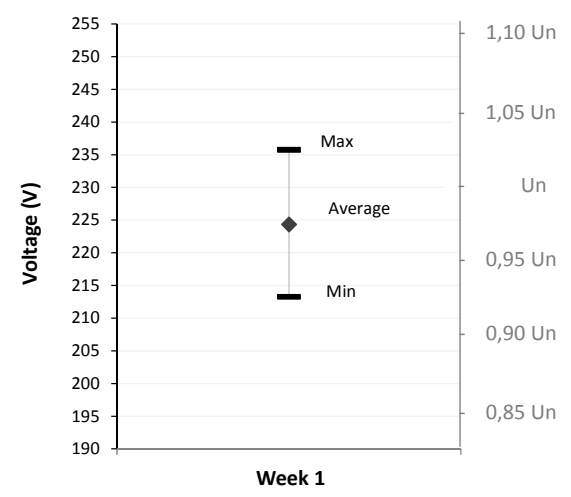

Fig. 11. Characterization of the supply voltage variations from one week.

As presented in Figure 12, the assembly of the results analysis for all the weeks monitored and for the three phases of the voltage gives rise to a more complete characterization of the supply voltage evolution along the year.

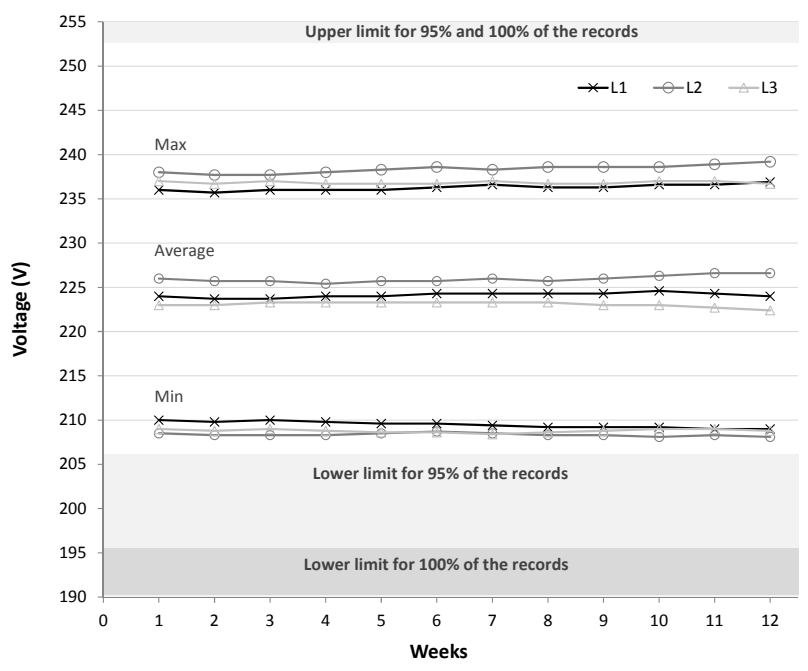

Fig. 12. Proposal for reporting the evolution of the supply voltage variations for a MV network point.

This approach, with some small adaptions (for instance, some voltage characteristics have only upper limits), can be applied to the other continuous phenomena and to the other voltage levels.

For the case of the harmonic voltages, since different limits are defined in the standard for each individual harmonic voltage, it is proposed to use THD evolution for the characterization.

\section{B. Voltage Events}

The present practice of the networks operators, in what concerns the publication of the voltage events, is to follow the tables defined for voltage dips and swells in the standard EN 50160: 2010.
However, since the main uses of this data is to increase the knowledge about voltage perturbations that affect customers installations and to design protection tools able to immunize those installations to the voltage events, the level of information in the tables defined by the standard EN 50160: 2010 may not be enough.

At moment, some discussion exists about an evolution of the table currently in use to report the voltage dips. That table does not distinguish between types of faults that are in the origin of the dips. A solution for this lack of information is to report the dips in different tables according to the number of phases involved in the fault [16].

However, the benefits of such solution are much dependent on the network point were measurements are done. If between the network measurement point and the customer installation exists a transformer with different connection types in first and second windings, the characteristics of the voltage dip affecting the customer are very different from the characteristics measured in the network.

\section{Conclusions}

In this paper, an overview on the Portuguese quality of electricity supply regulation was presented, with special a focus on the voltage quality topic.

The Portuguese code establishes the obligation of the network operators to develop voltage quality programs every two years with well-defined targets. In the year 2017 , it is expected that $100 \%$ of the transmission network delivery points will be covered by a combination of permanent and periodic campaigns (1 year).

The implementation of those voltage quality monitoring programs is producing a large number of data and results that network operators must make available for the public. For this purpose, each operator has developed his own methodology and not all of them include the publication of completely useful data for network users.

In order to give a contribution for reducing the lack of harmonization identified and to make the published results more useful, some guidelines were proposed for the publication of the results from voltage continuous phenomena monitoring.

Future developments in this topic will focus on the definition of new tables for voltage events reporting, according to the types of faults that are in the origin of such events.

\section{Disclaimer}

The text in this paper represents the personal opinion of the authors and not necessarily the opinion of the Portuguese regulatory authority for energy services (ERSE). 


\section{References}

[1] V. Ajodhia, and R. Hakvoort, "Economic regulation of quality in electricity distribution networks," Utilities Policy, vol. 13, pp. 211-221, Sep. 2005.

[4] D. Giannakis, T. Jamasb, and M. Pollitt, "Benchmarking and incentive regulation of quality of service: an application to the UK electricity distribution networks," Energy Policy, vol. 33, pp. 2256-2271, Nov. 2005.

[2] V. Ajodhia, L. Schiavo, and R. Malaman, "Quality regulation of electricity distribution in Italy: an evaluation study," Energy Policy, vol. 34, pp. 1478-1486, Sep. 2006.

[3] E. Fumagalli, P. Garrone, and L. Grilli, "Service quality in the electricity industry: the role of privatization and managerial behavior," Energy Policy, vol. 35, pp. 62126224, Dec. 2007.

[5] E. Fumagalli, L. Lo Schiavo, and F. Delestre, Service Quality Regulation in Electricity Distribution and Retail, Berlin: Springer, 2007.

[6] CEER - Council of European Energy Regulators, "Guidelines of Good Practice on the Implementation and Use of Voltage Quality Monitoring Systems for Regulatory Purposes”, Brussels, Dec. 2012.

[7] F. Villa, A. Porrino, R. Chiumeo, S. Malgarotti, The power quality monitoring of the MV network promoted by the Italian regulator. Objectives, organisation issues, 2006 statistics, $19^{\text {th }}$ International Conference on Electricity Distribution - CIRED, Vienna, 21-24 May 2007.
[8] CEER - Council of European Energy Regulators, "5th CEER Benchmarking Report on the Quality of Electricity Supply (2011)”, Brussels, Apr. 2012.

[9] ERSE - Entidade Reguladora dos Serviços Energéticos, Grupo de Acompanhamento da Qualidade de Serviço [Online]. Available: http://www.erse.pt/pt/electricidade/ qualidadedeservico/grupoRQS/Paginas/default.aspx

[10] REN - Rede Eléctrica Nacional, S.A., Qualidade de Energia Elétrica [Online]. Available: http://www.ren.pt/ptPT/o_que_fazemos/eletricidade/qualidade_de_energia_ele ctrica/

[11] L.C. Pinto and A. Tavares, Power quality of supply characterization in the Portuguese electricity transmission grid, CIRED conference, Stockholm 10-13 June 2013.

[12] J. Meyer, P. Schegner and G. Winkler, Efficient method for power quality surveying in distribution networks, CIRED conference, Turin 6-9 June 2005.

[13] Kema Consulting, "Premium Power Quality contracts and labelling”, Arnhem, Apr. 2007.

[14] EDP Distribuição - Energia, S.A., Qualidade de Energia Elétrica [Online]. Available: http://edp-distribuicao. waynext.com/

[15] CEVE - Cooperativa Eléctrica de Vale D’Este, Qualidade da Onda de Tensão 2014 [Online]. Available: http://www.ceve.pt/index.php?cat=108\&item $=2125$

[16] CIGRÉ, Technical Brochure "Working Group C4.110 Voltage Dip Immunity of Equipment and Installations", April 2010. 